\title{
An iterative approach to an integrated land use and transportation planning tool for small urban areas
}

\author{
Meiwu $\mathrm{AN}^{1}$, Mei $\mathrm{CHEN}^{2 *}$ \\ 1. Saint Louis County Department of Highways and Traffic and Public Works, 121 South Meramec Avenue, 8th Floor Saint Louis, \\ Missouri 63105, USA \\ 2. Department of Civil Engineering, University of Kentucky, Lexington, KY 40506-0281, USA
}

\begin{abstract}
There has been increasing interests in developing land use models for small urban areas for various planning applications such as air quality conformity analysis. The output of a land use model can serve as a major input to a transportation model; conversely, transportation model output can provide a critical input to a land use model. The connection between the two models can be achieved by an accessibility measure. This paper presents an iterative approach to solving a regression-based land use model and a transportation model with combined trip distributionassignment. A case study using data from a small urban area is presented to illustrate the application of the proposed modeling framework. Tests show that the procedures can converge, and the modeling framework can be a valuable tool for planners and decision-makers in evaluating land use policies and transportation investment strategies.
\end{abstract}

Key words: integrated land use and transportation model; urban model; travel demand model; combined trip distribution and assignment model; urban planning

(C) 2012 JMT. All rights reserved.

\section{Introduction}

$\mathrm{T}$ he growth of America's urban areas has been accompanied by deteriorating traffic conditions. Metropolitan Planning Organizations (MPOs) have been formed to oversee the comprehensive planning process for urbanized areas with population of more than 50000 . Regional or urban travel demand models have been created for medium and large MPO areas; they serve as tools for better evaluation of the long-term consequences of various land use and transportation policies. Having seen the growth associated problems encountered by larger metropolitan areas, citizens in smaller urban or MPO areas have been advocating for the preservation of the "small town atmosphere." However, the existing tools for modeling the interaction between land use and transportation system may not be applicable to these areas.

ITLUP and TELUM are gravity-based integrated urban models that have been deployed in many urban areas [1-4]. It assumes that the subject area is a closed system, i.e., most jobs in the study area are held by residents of the area; and most workers from local house-

Received Mar. 2, 2012; revision accepted May 28, 2012

*Corresponding author. E-mail: mchen@engr.uky.edu (M. CHEN) (C) 2012 JMT. All rights reserved doi: 10.3969/j.issn.2095-087X.2012.03.006 holds work in the same area. While this stands for large metropolitan regions, it may not be the case in smaller urban areas. For example, Woodford County, Kentucky, the small urban area studied in this paper, is located in central Kentucky between Lexington (the second largest city in Kentucky) and Frankfort (the state capital). Statistics show that $48 \%$ of the total jobs in the area are held by workers residing outside the area; about $55 \%$ of total workers in local households work outside the county. However, Woodford County does not belong to either one of the transportation management or MPO in the region. A tool is needed to accommodate the needs of areas alike.

MEPLAN and PECAS, another type of integrated urban models, were developed on the basis of input-output economic framework [5-7]. Its use of regionalized inputoutput models for economic and population distribution makes it better suited for inter-urban than intra-urban applications [8]. Its modeling structure suggests that its application on small urban areas is questionable [9].

The recently developed operational urban model UrbanSim requires an extensive amount of data at disaggregated levels spatially [10-12]. Very few regions or metropolitan areas routinely collect all the data needed by UrbanSim, not to mention smaller urban areas.

Transportation system as an important element in the urban systems significantly affects the urban form. Its interaction with urban activities has been well docu- 
mented. In large urban areas, travel demand models are available for the planners to evaluate the user and system impact of demographic and socioeconomic changes as well as various infrastructure investment decisions. To integrate land use and transportation planning, these models need to interface with land use modules in the urban model. For example, under the ITLUP setting, the location choice models for household and employment and the transportation model take each other's output as input, and a feedback loop should continue until the process converges. However, due to limited resources, the iterative feedback process is rarely executed even in large urban applications [3]. The development and maintenance of such urban models require substantial resource that small urban areas typically do not have.

This paper presents an iterative approach to an integrated land use and transportation planning model. The modeling framework is composed of a land use model and a transportation model. The former is a regressionbased model for household and employment distribution forecasting; the latter is a combined trip distribution and assignment model. Each model uses the outputs of the other as input for the next run. This framework does not implicitly require a closed system, and it is simple enough for small urban area applications. The concept is tested using data collected from Woodford County, Kentucky.

\section{Data}

With a population of 23208 and a total of 8893 households in the year 2000, Woodford County, Kentucky, is considered a small urban area. It contains 191 square miles mostly covered by rolling farmland and timber stands. There are 78 internal traffic analysis zones (TAZ) and 22 external TAZs, as shown in Fig. 1, which also contains the area road network. While adjacent to Lexington, Woodford County is not part of the Lexington area MPO.

Socioeconomic data, including population and employment, was obtained at the census block level and aggregated to the TAZ level. Population and household data was extracted from the 2000 Census data; employment data categorized by standard industrial classification codes was obtained from Dun \& Bradstreet employment survey data for the Commonwealth of Kentucky. In 2000 which is considered as the base year, there were 9486 jobs in the county, while many residents worked in the adjacent cities of Lexington and Frankfort.

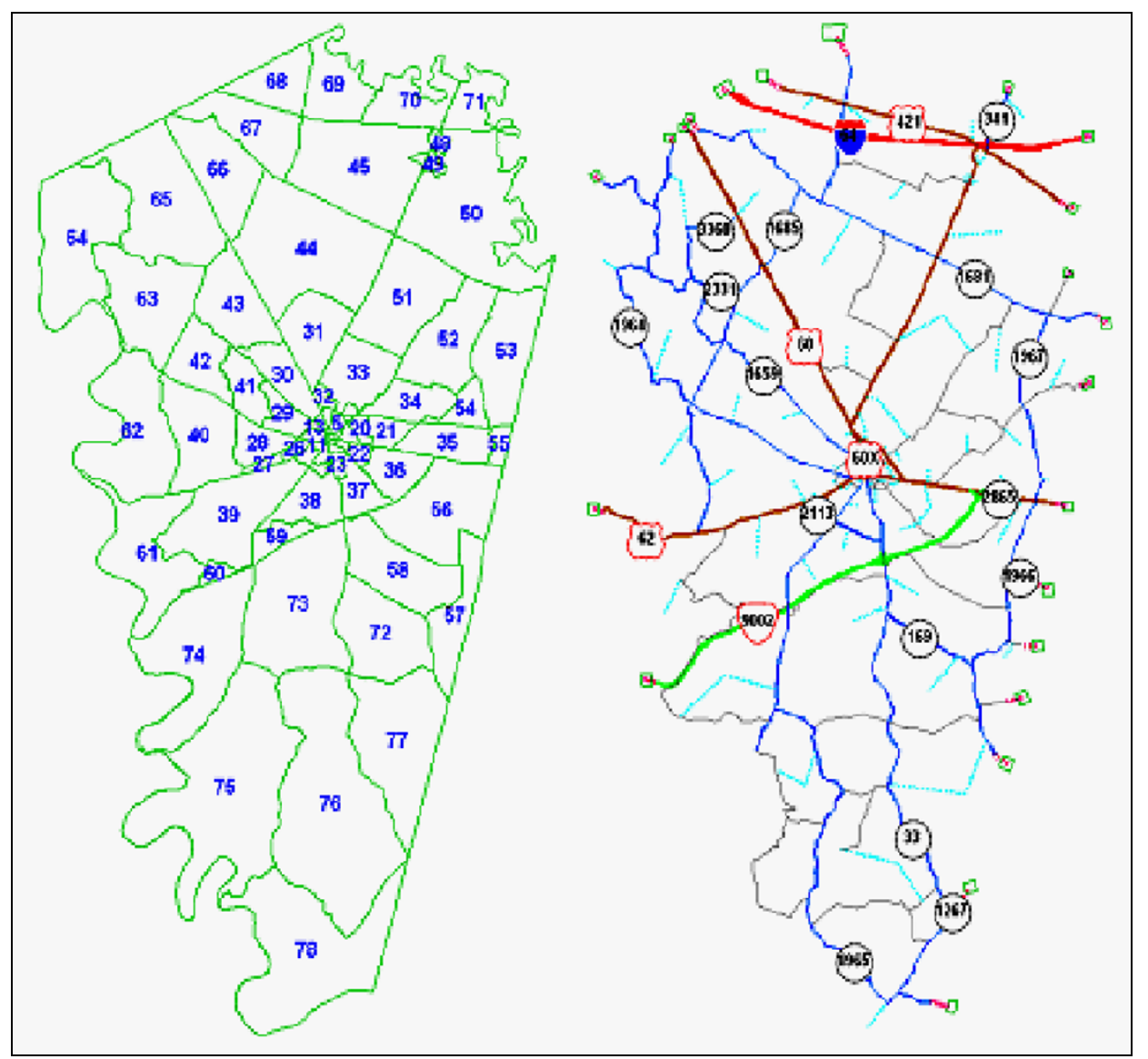

Fig. 1 Zones and road network of the study area 


\section{Land use model}

In this study, a land use model was developed to estimate household and employment distributions. Existing urban land use models are usually based on planning zones that are much larger than TAZs, which makes them unsuitable for application in smaller urban areas whose sizes are usually very limited. The land use model developed in this study uses TAZs as the planning zones for small urban areas. The setup enables the preservation of relatively detailed demographic and socioeconomic attributes of each zone.

To normalize the effect of the zonal size, household and employment densities rather than the actual numbers of households and jobs were used as indicators of their distributions. The density is defined as the number of households (or employees) per unit area. Literatures have shown that these densities are correlated with two major groups of factors; they are land use variables and transportation measures. The identification and analysis of these factors is discussed next followed by the modeling process.

\section{Variable specification}

Local land use data used in this study include land use types at the parcel level. Some of these types are residential, agriculture, industrial, commercial, professional office, vacant, etc. This information is available from the local planning/zoning agencies. In addition, a land use mix index (also known as land use balance, or entropy) was included to explore the potential effect of land use mix. This index is defined as

$$
\text { MixIndex }=-\frac{1}{\ln (n)} \sum_{i}^{n} F r_{i} \ln \left(F r_{i}\right)
$$

where $n$ is the total number of land use types under consideration and $F r_{i}$ is the fraction of land use type $i$. The land use mix index is a function of the land use fractions; its value ranges from 0 to 1 , where 0 indicates that a TAZ has only one type of land use and 1 indicates that all types of land uses have the same share in a TAZ [13].

Transportation measures to be considered shall be developed based on the characteristics of the study area. Such measures often include distance to major highways, travel time to downtown and nearby employment centers. In addition, a general accessibility term that measures the degree to which residents in a zone can reach or be reached by activities is used. There have been several ways to define the accessibility [14]. For example, in the household density model, accessibility measures the degree of ease with which the residents in a zone make trips to other zones in order to participate in relevant ac- tivities. It is directional proportional to the reachable opportunities at the destination zones and inversely proportional to the travel costs incurred in reaching those opportunities. A similar formulation to William [14] was used in this study:

$$
A C C H_{i}=\sum_{j} E_{j} \times \mathrm{e}^{-\beta c_{i j}},
$$

where $E_{j}$ is the number of jobs in zone $j$ of the study area; $\beta$ is an empirically determined coefficient in the trip distribution function; and $c_{i j}$ is the congested travel time between zones $i$ and $j$ of the study area.

\section{Land use model form}

The correlation between household/employment densities and land use/transportation measures were then explored. Various transformations such as logarithm, inverse, square, and exponential transformations were tested to find the one that fits best with each of the explanatory variables in the land use models. Various combinations of these variables were tested in the development process of land use model using methods such as forward selection, backward elimination, and stepwise selection. The following equation was chosen as the household density model with a coefficient of determination (Adjusted R Square) 0.87. It is indicated that $87 \%$ of variation in household density can be explained by

$$
\begin{gathered}
\text { Household Density }=64.762 \times \text { Fraction of } \\
\text { Residential Land }+0.224 \times \text { Accessibility } .
\end{gathered}
$$

One needs to be cautious when applying this model, since each of these two explanatory variables has its own physical meaning in the urban planning environment. For example, accessibility measure is always positive, which creates a situation where the estimated value of household density for a zone is always larger than zero even when there is no residential parcel at all in this zone. To avoid the inconsistency, this model is only applied to the zones with residential land use. For the zones without residential land parcel, household density is set to zero. The total number of households in zone $i$ can be estimated as

$$
H_{i}=\text { Area }_{i} \times\left(64.762 X_{i}+0.224 \sum_{j} E_{j} \mathrm{e}^{-\beta c_{i j}}\right) .
$$

For the employment density model, distance to major highways appears to be strongly correlated with employment density. However, it is important to note that employment distribution typically has a historical trend, or it is more exogenous than endogenous in the context 
of urban planning. For example, the ITLUP allocates employments into each planning zone based on previous employment distribution. Analysis on the Woodford County data showed that the current employment distribution (in year 2000) is strongly correlated with that in the previous periods. Meanwhile, the correlation between employment density and land use/transportation factors are not very significant. Therefore, in this study, the employment density was treated as an external input to the integrated land use and transportation modeling framework. Depending on the planning horizon, one can obtain employment estimates from previous years. It is also recommended that model results should be screened by local planning professional before they are put into transportation models.

The projected household and employment were then used as input to the estimation of trip generation. The interzonal travel time $\left(c_{i j}\right)$ term in the accessibility function is obtained from the transportation model which will be discussed in the next section.

\section{Transportation model}

\subsection{Formulation}

The transportation model in this study was formulated as a combined trip distribution and assignment model. This formulation has been studied extensively [15-17], and is considered to have performance advantage in some cases [18]. Effort has been made to incorporate land use factor into transportation model. For example, Meng et al. [19] extends the combined trip distribution and assignment model by linking a Lowrybased land use model to model home-based work trips.

This paper adopts the formulation of a combined trip distribution and assignment model and presents a case of complete calibration and application based on a practical network, including all trip purposes such as homebased work trips, home-based other trips, and nonhome-based trips.

$$
\operatorname{Min} \sum_{a} \int_{0}^{v_{a}} s_{a}(w) \mathrm{d} w+\frac{1}{\beta} \sum_{i} \sum_{j}\left(t_{i j} \ln t_{i j}-t_{i j}\right),
$$

s.t.

$$
\begin{aligned}
& \sum_{j} t_{i j}=O_{i}, \quad i \in I, \\
& \sum_{i} t_{i j}=D_{j}, \quad j \in J, \\
& \sum_{r \in R_{i j}} h_{r}=t_{i j}, \quad i \in I, \quad j \in J, \\
& v_{a}=\sum_{r \in R} h_{r} \delta^{a r}, \quad a \in A, \\
& h_{r} \geq 0, i \in I, \quad j \in J, \quad r \in R_{i j},
\end{aligned}
$$

where $v_{a}$ is defined as the traffic flow on link $a$, for $a \in A ; A$ is the set of links (road segments) in the network; $s_{a}()$ is the link performance function; $t_{i j}$ denotes the number of trips between origin $i$ and destination $j$ for $i \in I$ and $j \in J$, where $I$ and $J$ are the set of originating zones and the set of destination zones in the study area; $O_{i}$ denotes the trips originating from zone $i$, for $i \in I ; D_{j}$ denotes the trips destined to zone $j$, for $j \in J ; R_{i j}$ denotes the set of paths from origin $i$ to destination $j$, for $i \in I$ and $j \in J ; R$ is the set of complete paths that connect all OD pairs in this area. $R$ is defined as $R=\cup_{i} \cup_{j} R_{i j}$, for $i \in I$ and $j \in J ; h_{r}$ is defined as the number of trips on path $r$, for $r \in R ; \delta^{a r}$ denotes the incidence coefficient that describes the relationship between path and link. $\delta^{a r}=1$ if link $a$ is on path $r$; otherwise $\delta^{a r}=0$, for $a \in A$ and $r \in R$; and $\beta$ is the dispersion parameter for the trip distribution function, which is the same as the one in accessibility equations.

Trips with one end outside the area are considered external trips. They are treated as external variables and therefore are not included in the decision variables in the combined distribution/assignment problem. These trips are assigned to the network first and become the background traffic, which is included in the link travel time function. In this study, a typical BPR-type function in the form of

$$
s_{a}\left(v_{a}\right)=t t_{a}=t t_{a}^{f}\left[1+0.15\left(\frac{v_{a}+B G_{a}}{C P_{a}}\right)^{4}\right]
$$

is chosen as the link performance function, in which $t t_{a}$ and $t t_{a}^{f}$ is congested travel time and free-flow travel time, respectively; $B G_{a}$ is background traffic flow and $C P_{a}$ is the capacity of link $a$, for $a \in A$.

It has been proved that the solution of the combined trip distribution and assignment model satisfies the user equilibrium conditions [10, 12], which state that all used paths between an OD pair have equal travel time that are shorter than those on all unused paths. Therefore, no road user can unilaterally improve his/her travel time by switching paths. Adding background traffic to the link performance function has no impact on the optimality condition. The trip distribution function under the optimal condition of this optimization program is shown below:

$$
t_{i j}=\exp \left[\beta\left(\lambda_{i}+\sigma_{j}-u_{i j}\right)\right]=M_{i} B_{j} O_{i} D_{j} \mathrm{e}^{-\beta u_{i j}},
$$

where $\lambda_{i}, \sigma_{j}$, and $u_{i j}$ are the Lagrange multipliers for equations 4(b), 4(c), and 4(d); $M_{i}=\mathrm{e}^{\beta \lambda_{i}} / O_{i}$ and 
$B_{j}=\mathrm{e}^{\beta \sigma_{j}} / D_{j}$ are balancing factors that ensure the trip interchange output is consistent with the typical form of a gravity model. The travel impedance function in the trip distribution model is an exponential decay in the form of $f\left(u_{i j}\right)=\mathrm{e}^{-\beta u_{i j}}$, where $\beta$ is greater than zero.

\subsection{Calibration}

In this study, a complete calibration process using the data from Woodford County was presented to facilitate the application of the integrated modeling framework. Since the transportation model developed here is a daily model in which return trips should be accounted for. Therefore, the total origination trips and destination trips for a given zone should be equal. Origination and destination trips can be formulated as functions of household and employment as shown in Eq. (7). It is worth noting that $O_{i}$ and $D_{j}$ are completely different from trip production $(P)$ and trip attraction $(A)$ in a traditional fourstep travel demand model. In four-step model, trip productions refer to home-ends of trips and trip attractions represents non-home ends of trips regardless of whether home is origination or destination. For example, for home-based trips, trip production end may be the destination. In the combined trip distribution and assignment model, origination trips directly represent the trips which go out of a TAZ; destination trips refer to the trips which come to a TAZ.

$$
O_{i}=D_{i}=3.1369 H_{i}+1.2663 E_{i} .
$$

The calibration process mainly involves the determination of the value of $\beta$ in Eq. 4(a). This process is similar to that of the calibration of a gravity-type trip distribution model using the observed trip length distribution in the base year. The convergence threshold is set to $1 \%$ relative difference between the two consecutive iterations. The observed mean travel time can be defined as

$$
\overline{C_{*}}=\sum_{i j} t_{i j} c_{i j} / T
$$

where $c_{i j}$ is the observed travel time between OD pair from $i$ and $j(i \in I, j \in J)$, and $T$ is total trips in the study area. The calibration procedure can be constructed as follows:

(1) Initialize the value of $\beta$ as the inverse of the observed mean travel time.

(2) Apply the trip distribution model (Eq. (6)) associated with the given $O_{i}$ and $D_{j}$ to generate an estimated OD matrix.
(3) At iteration $k$, estimate mean travel time $\bar{C}_{k}$ using the same formula as $\overline{C_{*}}$ based on the new trip matrix obtained in step 2. Compare $\bar{C}_{k}$ and $\overline{C_{*}}$, if there's less than $1 \%$ difference between them then the convergence has been reached and the procedure stops. Otherwise, continue to step 4.

(4) Compute

$$
\beta_{k+1}=\frac{\left(\overline{C_{k}}-\overline{C_{*}}\right) \beta_{k-1}-\left(\overline{C_{*}}-\bar{C}_{k-1}\right) \beta_{k}}{\overline{C_{k}}-\bar{C}_{k-1}} .
$$

If $k=1$, then $\beta_{2}=\overline{C_{1}} \beta_{1} / \overline{C_{*}}$. Return to step 2 using the new $\beta$ value.

The iteration continues until the convergence criterion is met. In this study, the calibration process stopped after eight iterations, resulting in a $\beta$ value of 0.1993 .

\section{Linking land use and transportation models}

An iterative approach was established to link the land use and transportation models. This approach involves solving the land use and transportation problems iteratively using each other's outputs in the previous round. This feedback loop continues until certain convergence criteria are reached. In this study, the convergence criteria were specified as: in the two consecutive iterations, (1) less than $5 \%$ of OD pairs have OD trips variation of more than $5 \%$; (2) less than $5 \%$ of links have link flow variation of more than $5 \%$; and (3) less than $1 \%$ of zones have household distribution variation of more than $5 \%$. All three conditions need to be satisfied before the procedure can stop. The specific steps used are outlined below.

(1) Determine $E_{i}$ by solving the exogenous employment distribution model;

(2) Set initial values of $c_{i j}^{k-1}$ from the base year transportation model, and set $k=1$ where $k$ refers to the $k$-th iteration;

(3) Solve the household distribution model for $H_{i}^{k}$;

(4) Solve the combined trip distribution and assignment model for $v_{a}^{k}, t_{i j}^{k}$, and $c_{i j}^{k}$ using $E_{i}$ and $H_{i}^{k}$ as input;

(5) Check if the convergence criteria with respect to $H_{i}^{k}, v_{a}^{k}$, and $t_{i j}^{k}$ are satisfied. If yes, stop the iteration; otherwise replace $c_{i j}^{k-1}$ with $c_{i j}^{k}$ in step 2 and repeat steps (3)-(5).

This iterative approach was applied to the Woodford County land use and travel demand models described above. The convergence criteria were met after the $3 \mathrm{rd}$ iteration. The variations of measures such as link flows 
and OD volumes were tracked during the process. It appeared that the algorithm converged gradually during the three iterations. No significant oscillation of these measures was observed. Table 1 shows link flow variation between second and third iterations; Table 2 lists variation on OD trips; Table 3 displays variation on the number of households. These links, ODs, and zones are of the most interest and concern in the area. Note that although theoretically this iterative algorithm is not guaranteed to converge, it did rather quickly in this test. After the successful run using base year data, the iterative approach was applied to simulate potential outcome of land development decisions. A proposed development of a residential subdivision along a major road US60 was used for illustration purposes. The additional housing will cause the residential land use fraction of this zone (TAZ \#36 in Fig. 1) to increase from 36.4\% to $46.4 \%$. This new fraction was plugged into the household distribution model along with the base year travel time matrix to estimate the future household distribution. The iteration process continued between land use and transportation models until the convergence criteria were met. One should note that the employment distribution was exogenously determined in this modeling framework. Future employment distribution could be estimated externally according to regional development and local planning goals.
Table 1 Selected model output (link flow)

\begin{tabular}{lccc}
\hline Link & $\begin{array}{c}\text { Link flow } \\
\text { (third iteration) }\end{array}$ & $\begin{array}{c}\text { Link flow } \\
\text { (second iteration) }\end{array}$ & $\begin{array}{c}\text { Change } \\
\text { between two } \\
\text { iterations (\%) }\end{array}$ \\
\hline L196 & 6856 & 6855 & 0.0 \\
L679 & 6823 & 6828 & 0.1 \\
L356 & 6559 & 6557 & 0.0 \\
L143 & 6354 & 6352 & 0.0 \\
L133 & 6252 & 6240 & 0.2 \\
L707 & 6194 & 6193 & 0.0 \\
L110 & 6044 & 6031 & 0.2 \\
L111 & 6044 & 6031 & 0.2 \\
L158 & 5900 & 5890 & 0.2 \\
L633 & 5806 & 5792 & 0.2 \\
L634 & 5806 & 5792 & 0.2 \\
L105 & 5791 & 5778 & 0.2 \\
L106 & 5791 & 5778 & 0.2 \\
L107 & 5791 & 5778 & 0.2 \\
L108 & 5791 & 5778 & 0.2 \\
L109 & 5791 & 5778 & 0.2 \\
L632 & 5477 & 5462 & 0.3 \\
L409 & 5471 & 5456 & 0.3 \\
L403 & 5350 & 5348 & 0.0 \\
L636 & 5350 & 5348 & 0.0 \\
\hline
\end{tabular}

Table 2 Selected model output (OD trips)

\begin{tabular}{|c|c|c|c|c|}
\hline Origination & Destination & OD trips (third iteration) & OD trips (second iteration) & Change between two iterations (\%) \\
\hline $\mathrm{Z74}$ & $\mathrm{Z75}$ & 1431 & 1432 & 0.1 \\
\hline $\mathrm{Z75}$ & $\mathrm{Z74}$ & 1431 & 1432 & 0.1 \\
\hline $\mathrm{Z72}$ & $\mathrm{Z73}$ & 850 & 845 & 0.6 \\
\hline $\mathrm{Z73}$ & $\mathrm{Z72}$ & 850 & 845 & 0.6 \\
\hline Z36 & Z56 & 587 & 587 & 0.0 \\
\hline Z56 & Z36 & 587 & 587 & 0.0 \\
\hline Z65 & Z64 & 586 & 586 & 0.0 \\
\hline Z64 & Z65 & 586 & 586 & 0.0 \\
\hline $\mathrm{Z76}$ & Z78 & 566 & 566 & 0.1 \\
\hline $\mathrm{Z73}$ & $\mathrm{Z72}$ & 850 & 845 & 0.6 \\
\hline $\mathrm{Z78}$ & Z76 & 566 & 566 & 0.1 \\
\hline Z64 & Z62 & 502 & 503 & 0.2 \\
\hline Z62 & Z64 & 502 & 503 & 0.2 \\
\hline $\mathrm{Z75}$ & Z76 & 365 & 365 & 0.1 \\
\hline Z76 & $\mathrm{Z75}$ & 365 & 365 & 0.0 \\
\hline Z56 & $\mathrm{Z} 72$ & 356 & 356 & 0.0 \\
\hline $\mathrm{Z72}$ & Z56 & 356 & 356 & 0.0 \\
\hline Z76 & Z75 & 365 & 365 & 0.0 \\
\hline $\mathrm{Z73}$ & Z56 & 339 & 347 & 2.4 \\
\hline Z56 & $\mathrm{Z73}$ & 339 & 347 & 2.4 \\
\hline $\mathrm{Z} 37$ & Z36 & 330 & 330 & 0.0 \\
\hline Z36 & $\mathrm{Z} 37$ & 330 & 330 & 0.0 \\
\hline
\end{tabular}


Convergence was again reached after three iterations. Reasonable outputs were produced by the iterative procedure. The number of households in this TAZ increased from 1180 to 1440 due to the development. The subdivision development is surrounded by two major eastwest roads. One is US60, and the other is Huntertown road. The vehicle trips generated by the new development are distributed to US60 east to Lexington, US60 west to Frankfort and Versailles, Huntertown east to Lexington, Huntertown west to Frankfort and Versailles. Detailed analysis on peak hour traffic pattern indicated that the additional 260 households do not appear to have a significant impact on the congestion level of the network because the network is not congested in the future in this study area. It generates 1627 daily traffic of which 53 vehicle trips are distributed to US60 east increasing the road segment's $\mathrm{V} / \mathrm{C}$ ratio from 0.76 to $0.77 ; 451$ vehicle trips are allocated to US60 west raising the road segment's $\mathrm{V} / \mathrm{C}$ ratio from 0.68 to $0.70 ; 730$ vehicle trips are distributed to Huntertown east increasing its $\mathrm{V} / \mathrm{C}$ ratio from 0.27 to $0.33 ; 393$ vehicle trips are allocated to Huntertown west raising its $\mathrm{V} / \mathrm{C}$ ratio from 0.33 to 0.36 .

Table 3 Selected model output (number of households)

\begin{tabular}{|c|c|c|c|}
\hline Zone & $\begin{array}{c}\text { Household } \\
\text { (third iteration) }\end{array}$ & $\begin{array}{c}\text { Household } \\
\text { (second iteration) }\end{array}$ & $\begin{array}{c}\text { Change } \\
\text { between two } \\
\text { iterations } \\
(\%)\end{array}$ \\
\hline 56 & 1635 & 1635 & 0.0 \\
\hline 73 & 1335 & 1328 & 0.6 \\
\hline 72 & 1257 & 1255 & 0.2 \\
\hline 36 & 1180 & 1179 & 0.0 \\
\hline 75 & 1163 & 1163 & 0.0 \\
\hline 74 & 1045 & 1045 & 0.0 \\
\hline 38 & 1027 & 1026 & 0.0 \\
\hline 33 & 839 & 836 & 0.3 \\
\hline 64 & 809 & 809 & 0.0 \\
\hline 62 & 733 & 733 & 0.0 \\
\hline 58 & 579 & 576 & 0.4 \\
\hline 37 & 578 & 578 & 0.0 \\
\hline 50 & 575 & 573 & 0.4 \\
\hline 39 & 572 & 571 & 0.2 \\
\hline 51 & 472 & 469 & 0.6 \\
\hline 76 & 459 & 458 & 0.2 \\
\hline 61 & 453 & 452 & 0.1 \\
\hline 32 & 435 & 435 & 0.0 \\
\hline 30 & 384 & 384 & 0.1 \\
\hline 29 & 377 & 377 & 0.1 \\
\hline
\end{tabular}

\section{Conclusions}

In this paper, an integrated land use and transportation modeling framework is introduced. The framework contains a land use model in linear form and a transportation model in the form of a combined trip distribution and assignment problem. The models run alternatively and use the output of each other in the previous round as input. This feedback process stops when convergence criteria are met. A complete case study is provided to illustrate its application potential. The models are calibrated using base year data and can be used to estimate future scenarios. Although the convergence of this iterative procedure is not guaranteed in theory, the case study does show a quick convergence on a set of reasonably stringent criteria.

The application of the proposed land use model is particularly suitable for smaller urban areas with limited resources. Compared to comprehensive land use models implemented in large metropolitan areas, the land use model introduced here is simpler. The model framework presented in the study can serve as a tool to evaluate the consequences of land use policy and transportation investment decisions.

\section{References}

[1] S. H. Putman, Integrated Urban Models: Policy Analysis of Transportation and Land Use, London: Pion, 1989.

[2] S.H. Putman, Results from implementation of integrated transportation and land use models in metropolitan regions, In: Network Infrastructure and the Urban Environment, New York: Springer, 1988.

[3] S.H. Putman Associates, Inc., Integrated transportation and land use forecasting: sensitivity tests of alternative model systems configuration, Washington D.C.: U.S. Department of Transportation, 2001.

[4] C.T. Casper, J. O'Brien, M.R. Lupa, et al., Application of TELUM by the Pikes Peak, Colorado, Area Council of Governments lessons Learned in Colorado Springs, Transportation Research Record, 2009, 2119: 45-53.

[5] J.D Hunt, D.C. Simmonds, Theory and application of an integrated land-use and transport modeling framework, Environment and Planning B: Planning and Design, 1993, 20(2): 221-224.

[6] J.D. Hunt, Calibrating the Naples land-use and transport model, Environment and Planning B: Planning and Design, 1994, 21(5): 569-590.

[7] J.D. Hunt, J.E. Abraham, D. de Silva, et al., Developing and applying a parcel-level simulation of developer actions in Baltimore, In: Proceeding of the 87th Annual Meeting of the Transportation Research Board, Washington D.C., 2008.

[8] Parsons Brinckerhoff Quade \& Douglas, Inc., Land use impact of transportation: a guidebook, Washington D.C.: National Research Council, 1998. 
[9] J.D. Lemp, B. Zhou, K.M. Kockelman, et al., Visioning vs. modeling: analyzing the land use-transportation futures of urban regions, In: 86th Annual Meeting of the Transportation Research Board, Washington D.C., 2007.

[10] P. Waddle, UrbanSim: modeling urban development for land use, Journal of the American Planning Association, 2002, 68(3): 297-314.

[11] P. Waddell, J. Franklin, J. Britting, UrbanSim: development, application and integration with the Wasatch front regional travel model, Salt Lake City: Wasatch Front Regional Council, 2003.

[12] P. Waddell, X.L. Liu, L.M. Wang, UrbanSim: an evolving planning support system for evolving communities, Planning Support Systems for Cities and Regions, Cambridge: Lincoln Institute for Land Policy, 2008.

[13] K.M. Kockelman, Travel behavior as a function of accessibility, land use mixing, and land use balance: evidence from the San Francisco bay area, Transportation Research Record, 1997, 1607: 117-125.

[14] E.J. Miller, Land use transportation modeling, In: Transportation Engineering Handbook: Planning Methods and Applications, Florida: CRC Press LLC, 2004

[15] Y. Sheffi, Urban Transportation Networks: Equilibrium Analysis with Mathematical Programming Methods, Englewood Cliffs: Prentice-Hall, 1992.

[16] D.E. Boyce, L.J. Leblanc, K.S. Chon, Network equilibrium models of urban location and travel choices: a retrospective survey, Journal of Regional Science, 1988, 28(2): 159-183.

[17] H.C.W.L. Williams, On the formation of travel demand models and economic evaluation measures of user benefit, Environment and Planning A, 1977, 9(3): 285-344.

[18] Z.A. Shahriar, A. Morteza, M. Abolfazl, Combined trip distribution and assignment model: applications to captive trips, In: 87th Annual Meeting of the Transportation Research Board, Washington D.C., 2008.

[19] Q. Meng, H. Yang, S.C. Wong, A combined land-use and transportation model for work trips, Environment and Planning B: Planning and Design, 2000, 27(1): 93103.

(Editor: Yao ZHOU) 